\title{
Innovation Assessment
}

\section{Governing Through Periods of Disruptive Technological Change}

Hasselbalch, Jacob

Document Version

Accepted author manuscript

Published in:

Journal of European Public Policy

DOI:

10.1080/13501763.2017.1363805

Publication date:

2018

License

Unspecified

Citation for published version (APA):

Hasselbalch, J. (2018). Innovation Assessment: Governing Through Periods of Disruptive Technological Change. Journal of European Public Policy, 25(12), 1855-1873. https://doi.org/10.1080/13501763.2017.1363805

Link to publication in CBS Research Portal

\section{General rights}

Copyright and moral rights for the publications made accessible in the public portal are retained by the authors and/or other copyright owners and it is a condition of accessing publications that users recognise and abide by the legal requirements associated with these rights.

Take down policy

If you believe that this document breaches copyright please contact us (research.lib@cbs.dk) providing details, and we will remove access to the work immediately and investigate your claim. 


\section{Innovation Assessment: Governing Through Periods of Disruptive Technological Change}

\section{Jacob Hasselbalch}

Journal article (Accepted manuscript*)

\section{Please cite this article as:}

Hasselbalch, J. (2018). Innovation Assessment: Governing Through Periods of Disruptive Technological Change. Journal of European Public Policy, 25(12), 1855-1873. 001: 10.1080/13501763.2017.1363805

This is an Accepted Manuscript of an article published by Taylor \& Francis in Journal of European Public Policy on 17 Aug 2017, available online:

DOl: http://www.tandfonline.com/10.1080/13501763.2017.1363805

* This version of the article has been accepted for publication and undergone full peer review but has not been through the copyediting, typesetting, pagination and proofreading process, which may lead to differences between this version and the publisher's final version AKA Version of Record. 


\title{
Innovation assessment: governing through periods of disruptive technological change
}

Jacob A. Hasselbalch

Published at Journal of European Public Policy: http://dx.doi.org/10.1080/13501763.2017.1363805

\begin{abstract}
Current regulatory approaches are ill-equipped to address the challenges of governing through periods of disruptive technological change. This article hones in on the use of assessment regimes at the level of the European Union, particularly in the work of the Commission, to argue for a missing middle between technology assessment and impact assessment. Technology assessment focuses on the upstream governance of science and technology, while impact assessment focuses on the downstream governance of the impacts of specific policy options. What is missing is a form of midstream governance, which I label innovation assessment, to steer polities through periods of disruptive technological change, during which innovations have taken concrete forms and are beginning to diffuse, but still exhibit much scope for rapid, unexpected change and alternative trajectories of development. By juxtaposing these three forms of assessment regimes, I define the main dimensions along which they vary.
\end{abstract}

KEYWORDS: disruptive innovation, governance, impact assessment, innovation assessment, technology assessment, policy appraisal 


\section{Introduction}

There is a growing sense of unease among the policymaking élite that they are increasingly placed on the back foot when it comes to addressing disruption, innovation and technological change, forced to suddenly react to such changes rather than shape them from the outset. We can observe this in, among other things, the increasing prevalence of the term 'disruption' in popular and political discourse. This observation challenges the governing logic of the relationship between regulation and innovation, namely that the purpose of regulation is to promote and support innovation, because more innovation is generally assumed to be a good thing.

In the public policy of the European Union, recent attempts to promote innovation through regulatory policy include the establishment of national productivity boards (Council of the European Union 2016b) and the re-alignment of the Better Regulation Agenda with competitiveness (Council of the European Union 2016a) and innovation-driven investment (European Commission 2016). The Commission has also been developing an 'Innovation Principle' to rival the 'Precautionary Principle', arguing for greater attention to the impact on innovation during the development of any policy initiative (European Political Strategy Centre 2016). What these initiatives all have in common is an assumption that the causal relationship between regulation and innovation goes only one way: regulation acts on innovation, and not the other way around. But what happens when innovations act on regulation?

Innovations often lead to accelerating changes, disruptions, and fundamental challenges for the economy, society, and policymakers that demand sweeping regulatory responses. Consider innovations such as hydraulic fracturing (fracking), electronic cigarettes, digital piracy, shadow banking, or ridesharing services (e.g., the taxi app Uber). These innovations are disruptive not only in the business or 
management sense of impacting the dynamics of market competition in their respective sectors (Christensen 1997), but also in the political sense of provoking intractable and highly contested policy and regulatory issues that invite media scrutiny and mobilise the public. For example, the recent revision in the European Union (EU) to the Tobacco Products Directive nearly failed due to disagreements concerning the scope of regulatory action needed on e-cigarettes (Hasselbalch 2016). Similarly, fracking has instigated intense political debates about the sufficiency of current environmental regulation to mitigate the risks of contamination to air and groundwater. And Uber has been the target of countless strikes and demonstrations, sometimes violent, across Europe. Disruptions clearly have a tendency to become political, and due to their border-spanning effects, these politics are often decided on a European level. And on the national level, domestic politicians frequently take their cues from European directives or policies.

When we reverse the governing logic of the innovation-regulation relationship, we can ask how innovations act on regulation and what that means. Specifically, this introduces disruptive innovations as a class of policy problems in their own right that present policymakers with a unique set of challenges. In this article, I focus on the regulatory uses of assessment regimes to respond to the challenges of disruption, arguing that there is a missing middle between technology assessment and impact assessment that can and should be filled by a novel form of 'innovation assessment'. The article takes the first steps on this path by defining the problem and sketching out the main principles and sources of inspiration on which innovation assessment can be constructed.

The next section defines assessment regimes and maps them on to the innovation life cycle. Section 3 then juxtaposes technology assessment with impact assessment to demonstrate the existence of a missing middle in assessment regimes, both in terms of policy imagination and institutional 
architecture. Section 4 defines the key principles to which innovation assessment should adhere in order to productively explore this middle ground. I summarise these principles in Table 1, which illustrates the six main dimensions along which technology assessments, innovation assessments, and impact assessments vary. I also reflect on a few different sources of inspiration for turning these principles into specific governance arrangements (experimentalist governance, orchestration, responsible research and innovation, and agile governance). Section 5 concludes the article.

\section{Assessment Regimes}

In attempting to meet the challenges of disruptive innovations, policymakers initially need to gather information on the nature and expected impacts of the disruptions in order to figure out what they are looking at. They do so through 'assessment regimes' (Kaiser et al. 2010): various kinds of actions that are taken to estimate benefits, risks, and public attitudes, engage stakeholders in discussion, and provide evidence for policymaking and regulation. Assessment is not the same as doing research rather, it is the 'the presentation of knowledge derived from research to help someone with responsibilities evaluate possible actions or think about a problem' (Parson 1995: 463). As such, assessment involves 'assembling, summarising, organising, interpreting, and possibly reconciling pieces of existing knowledge, and communicating them so that they are relevant and helpful for the deliberations of an intelligent but inexpert policy maker' (ibid.).

When we consider the repertoire of assessment regimes such as impact assessment, ethical assessment, risk analysis, foresight, scenario planning, technology assessment, and future-oriented technology analysis, it is clear that different types of assessments are associated with different stages of the technology and policy life cycle. Early assessments more openly deliberate values and possible 
trajectories, while later assessments focus on settling risk assessment and regulatory issues (Forsberg et al. 2014: 312). Assessment regimes such as scenario planning, foresight, technology assessment, ethical assessment, and future-oriented technology analysis are thus aimed at the earliest stages of the technology and policy life cycle, while regimes such as impact assessment and risk analysis are more aimed at the later stages. Early stage assessments 'open up' the societal appraisal of innovations (by enrolling stakeholders to discuss a range of different outcomes and policy options) and late stage assessments 'close them down' (by relying more heavily on expert analysis and calculation to legitimate commitments to policy choices) (Stirling 2008).

Early and late-stage assessments map on to the innovation life cycle. The process of innovation is often viewed as a 'stream', where innovations flow from early-stage science and research to laterstage innovations in the form of concrete products or services that diffuse through market channels (Lundvall and Borrás 2005). Upstream governance of the innovation stream straightforwardly refers to the early-stage assessments that are well-suited to unveiling and addressing broader issues pertaining to the science and technologies that may underlie future innovations - and downstream governance, vice versa, works well when innovations are mature products with well-established risk profiles (Fisher et al. 2006). But this picture breaks down when it comes to disruptive innovations.

Disruptive innovations are neither early-stage technologies that can be highly reconfigured to suit different needs, but neither are they mature, late-stage products with somewhat settled or wellknown trajectories of onward development. Early-stage assessments, when applied to disruptive innovations, will be doing too little, too late, but late-stage assessments will be doing too much, too early. The argument this article sets out is a straightforward 'Goldilocks' story: for dealing with the regulatory challenges of disruptive innovations, technology assessment is too cold (or too late) and 
impact assessment is too hot (or too early). We need something in the middle, neither too hot nor too cold, which I propose to label 'innovation assessment'. Before 'technologies' become 'impacts', there is a period of 'innovation', where technologies have taken specific, marketable forms, but are still open to a number of different trajectories of onward development (although fewer than during the technology phase). This requires a different form of assessment and steering. In the following, I employ technology assessment as an overall label for early-stage assessment regimes and impact assessment as a label for late-stage assessment regimes.

\section{Technology Assessment versus Impact Assessment}

If we picture innovation as a boat sailing down a stream, then the upstream governance of technology assessment is useful for charting an initial course as the boat departs harbour, and the downstream governance of impact assessment brings the boat safely back to shore. But currently nobody is steering the boat through the stream - which is the same as saying that we need an assessment regime that works for steering innovations through their disruptive periods.

In economics, disruption tends to be conceptualised as a one-off, exogenous shock, but this is an inadvisable position to take for policy studies, as it makes it impossible to study the process of change itself (Kay 2005). When we think of disruption as an entirely endogenous process that unfolds through iterations of social interaction and readjustment between innovators, incumbents, regulators, and publics, we can make those interactions the subject of social and political inquiry (Vollmer 2013). Current regulatory logics are ill-equipped to deal seriously with this temporal duration of disruption. Technology assessment tries to anticipate all possible trajectories that innovations can take ex ante impact assessment reacts to the expected outcomes of the innovation ex post. Both of these logics are 
artefacts of viewing disruption as a shock, when in reality we would gain much by imagining and realizing a greater scope for regulatory actions taken during the innovation phase to help guide innovations towards societally desired goals.

'Studying assessments across advisory domains is a practically non-existent research field' (Forsberg et al. 2014). This is an unfortunate lacuna in public policy, as assessments are given increasingly more weight in determining and validating policy options (Dunlop et al. 2012). While impact assessments fall within the scope of policy appraisal, on which there is a growing literature within public policy (Adelle et al. 2012), technology assessments do not, as they are not necessarily connected to a specific policy initiative and are further removed from the legislative process. As such, technology assessment has not received much attention by European public policy scholars, who mostly leave the topic to the field of science and technology studies. In juxtaposing the two here under the common label of assessment regime, I aspire to instigate a broader conversation about how innovations are made sense of by policymakers and with what effects for the policy process.

Assessments are inherently political - they are important sites of political behaviour with their own institutions, instruments, and actors. Policymakers make choices between different assessment types and also have to weigh, integrate, and synthesise findings from different assessments (or different bodies of evidence within the same assessment) (Forsberg et al. 2014). Furthermore, policymakers can be strategic in their choice of opting for either early-stage assessments to open up the policy debate or late-stage assessments to close it down (Stirling 2008). Consequently, disruptive innovations tend to be shoehorned into either a technology assessment logic or an impact assessment logic. These two approaches are in opposition to each other, implying different policy instruments, different logics, and 
different assumptions and conceptions of technology and innovation. Neither is suitable for dealing with the unique regulatory challenges of disruptive innovations.

\subsection{Technology assessment}

The purpose of technology assessment (TA) is to contribute to the formation of public and political opinion on the societal aspects of technologies via a structured, deliberative process, typically including engagement with citizens, stakeholders, and experts. Almost since its beginnings, there have been strong challenges to the idea that TA as a policy-scientific tool produces objective judgments on the future impacts of technologies on society (Wynne 1975). TA has progressed through several iterations and branched into disparate but connected streams all with a view to rectifying the initial assumptions that favoured an arguably unattainable ideal of sound science, impartial experts and a Habermasian public sphere (Ely et al. 2014). These streams are concerned with the various ways in which the practice might be 'broadened out' to include wider representations of viewpoints as inputs to the process and 'opened up' to produce more diverse forms of output from the process that are communicated to a larger audience. TA is ultimately about shaping the direction that research, science and technology should take, meaning that the focus is on foresight and intervention before the technology is marketed. Traditionally, TA takes place within dedicated agencies, such as the now defunct U.S. Office of Technology Assessment, which was the first such agency to be established.

In the EU, there are still a number of very active TA agencies supporting domestic parliaments. Some of the more influential ones include the Danish Board of Technology Foundation, the Swiss Centre for Technology Assessment, the Rathenau Institute at The Hague, the Parliamentary Office of Science and Technology in the United Kingdom, and the Austrian Institute of Technology Assessment. These agencies, including a number of others, make up the European Parliamentary Technology 
Assessment (EPTA) network, through which its members cooperate their efforts towards making TA an integral part of policy formation in parliamentary decision-making. The European Parliament (EP) has their own TA agency in the form of the Science and Technology Options Assessment (STOA) Panel. STOA supports the EP's Committees by providing access to expert assessments of various scientific or technological options - it commissions those assessments from members of the European Technology Assessment Group, made up of eight European TA agencies, most of which are also in the EPTA network (Delvenne et al. 2011). It remains a voluntary procedure, however, to be initiated by the Committees.

Common to all the threads of technology assessment and FTA is the focus on upstream governance and on shaping trajectories from the earliest possible stage. Other than that, however, the many different varieties of TA have very little in common, and it is difficult to say anything in general about the methodologies they follow. Each TA agency relies on unique, ad hoc mixtures of methods to carry out assessments, including reviews of the scientific literature, expert opinions, consensus conferences, citizen juries, the Delphi method, and so on (Delvenne et al. 2011).

Newer forms of technology assessment, especially inspired by the Dutch and Danish traditions (Ely et al. 2014), are reconceptualising the practice as a more co-operative undertaking that enrols government agencies, academia, industry and other stakeholders into the practice. The term FutureOriented Technology Analysis (FTA) has emerged as one label to denote these newer forms, including a wider range of decision-preparatory tools such as foresight, forecasting, scenario planning, and so on (Cagnin et al. 2013: 381). These tools are being recognised for their potential to address disruption (ibid.) and emerging technologies (Schaper-Rinkel 2013), and the term is enjoying recognition within the European Commission. For example, the Commission's Joint Research Centre (JRC) has hosted a 
series of FTA conferences (e.g., European Commission 2014), and the European Strategy and Policy Analysis System (ESPAS) has been set up as an inter-institutional initiative tasked with forecasting and analysing future trends (European Strategy and Policy Analysis System 2015).

While interest is growing, technology assessment is not strongly institutionalised in EU rules and procedures. The parliamentary TA possibilities mentioned above remain just that: voluntary possibilities. And for the Commission, its interest in TA is motivated by an analysis of the farther future rather than meeting the immediate concerns raised by disruptions.

\subsection{Impact assessment}

Whereas technology assessment is concerned with opening up and deliberating the various trajectories that a technology might take, impact assessment is concerned with closing off different policy options by approximating the effects of a number of specified regulatory initiatives. Impact assessments (IA) have been an integrated part of the European policymaking process since 2003, and their use has been steadily increasing since then (Torriti 2010). The purpose of IA is to approximate the impacts of policy in economic, social, and environmental terms. By assessing impacts in terms of costs, benefits, and risks and including stakeholder opinions, they are meant to lay the groundwork for evidence-based policy - as such, they are an integral part of the 'Better Regulation Agenda' (European Commission 2015a). Impact assessments are strongly institutionalised within the Commission, as they are 'required for Commission initiatives that are likely to have significant economic, environmental, or social impacts' (European Commission 2015b). The role of impact assessments within the Commission has recently been strengthened with the replacement of the Impact Assessment Board by the Regulatory Scrutiny Board, whose powers and responsibilities have been expanded compared to its predecessor (Dinan 2016). 
Impact assessments are carried out by the lead Directorate-General (DG) of a regulatory initiative, and it is the responsibility of that DG to determine whether an IA is necessary for a specific policy proposal. If it is deemed necessary, an initial IA, called an 'Inception IA', provides a first description of the problem and possible policy solutions (European Commission 2015b). On the basis of this preliminary work, a decision is taken as to whether to proceed with a full IA. If a full IA is decided on, seven main steps follow: (1) The first step is to create an inter-service group (ISG), with participation from other DGs and often chaired by the Secretariat-General (SG), to steer the process. (2) The ISG then finalises the Inception IA and makes it publicly available in order to gather feedback from stakeholders. (3) A consultation strategy is formulated, including a mandatory 12-week internetbased open public consultation. (4) Data, including both stakeholder input and scientific and expert advice, is gathered and analysed, and (5) on the basis of the inputs so far an IA report is drafted. (6) The draft IA is submitted to the Regulatory Scrutiny Board for review and subsequently revised to address their recommendations. (7) Finally, the IA is submitted together with the policy initiative to inter-service consultation.

Impact assessments must answer the following questions (European Commission 2015b): (1) What is the problem and why is it a problem? (2) Why should the EU act? (3) What should be achieved? (4) What are the various options to achieve the objectives? (5) What are their economic, social and environmental impacts and who will be affected? (6) How do the different options compare in terms of their effectiveness and efficiency (benefits and costs)? (7) How will monitoring and subsequent retrospective evaluation be organised? These questions are what supply the structure to the 'narrative arc' of impact assessments: 'They present a problem and show how the situation will 
substantially improve, thanks to the initiative suggested by the Commission' (Radaelli et al. 2013: $502)$.

What these seven steps and seven questions make clear is that the IA as a practical and welldefined toolkit for policy appraisal is highly integrated into the framework of the Commission's legislative process. It is also clear that the primary purpose of the IA is to ensure that EU policy initiatives are commensurate with the perceived scale of a specific problem that needs addressing. In the context of the Better Regulation Agenda and the REFIT platform (the regulatory fitness and performance programme), it is no surprise that IAs are growing in importance within the Commission (Dinan 2016).

The growing importance of IAs within the Commission has not escaped the attention of academics (Adelle et al. 2012). Some studies especially bring light to the 'regulatory oversight dimension', that is, the scope IAs allow for political control of the bureaucracy. For example, Radaelli et al. (2013) and Torriti (2010) have pointed out the tendency for some uses of IA to serve merely legitimizing functions in the service of pre-defined political ends. The strengthening of the Regulatory Scrutiny Board and the REFIT platform may be understood as direct responses to these concerns. In this context, a redoubling of efforts to scrutinise the politics of assessment regimes in general seems warranted, and these efforts should not be limited to just impact assessments, but engage more broadly with the various ways that the Commission structures and narrates the results of various forms of assessment exercises.

\subsection{The missing middle of assessment regimes}

Having considered the differences between the upstream governance of technology assessment and the downstream governance of impact assessment, it becomes clear that there is a missing middle into 
which disruptive innovations plummet. I mean this in two ways: there is a missing middle both in terms of the policy imagination and in terms of the institutional architecture.

Regarding the policy imagination, disruptive innovations can either be conceived of as technologies or as impacts. If we view them as technologies, they fall under the TA regime, and attention turns away from their immediate applications and market diffusion towards longer-term trajectories and possible use scenarios. This opens the debate too widely and turns it towards questions of science and technology - in other words, TA moves the innovation 'boat' too far back upstream. On the other hand, if we view disruptive innovations as impacts, we are moved too far downstream. Impact assessment demands that innovations are stable, predictable, and mature in order for the cost-benefit analyses to be calculable and credible. And if innovations are turned into impacts, then their scope for developing along new and unexpected trajectories is removed from consideration. This runs the risk of impact assessments going very wide of the mark or misunderstanding the possible future applications of an innovation.

Regarding the institutional architecture, we are left with assessment regimes that are either under-institutionalised or over-institutionalised for the purpose of addressing disruptive innovations. TA remains a voluntary option and is mostly associated with Parliamentary initiatives. IA is inextricably linked to specific policy proposals set forward by the Commission, and as such only applies to the extent that a certain disruption has already been identified and targeted in the work programme. Also here, we would be better served with something in-between the two.

The problem with shoehorning disruptive innovations into either technology assessment or impact assessment lies not only in the inaccuracy of the assumptions brought to bear on what innovations are and how they develop. The construction of this dichotomy between technologies and 
impacts, whether conscious or unconscious, also absolves regulators of certain responsibilities due to the dual challenges of salience and uncertainty (Radaelli 1999). Disruptive innovations are both highly salient and highly uncertain, but technology assessments and impact assessments each address just one of the two challenges. Technology assessment reduces salience by opening up the policy debate to contending viewpoints, but granting a too large space of possibilities for future technological trajectories. This does little to address uncertainty, thereby running the risk of populism, where political opinion trumps expert advice. On the other hand, impact assessment reduces uncertainty by closing down the policy debate and ranking policy options according to cost-benefit calculations. This exercise does little to address salience and runs the risk of expert advice trumping political opinion. Because both forms of assessment are susceptible to framing, policy actors can be strategic in pressuring for the populist or technocratic viewpoint, frequently at odds with each other on controversial policy issues, to carry the day (Stirling 2008). Innovation assessment needs to meet the dual challenges of salience and uncertainty head-on.

\section{Defining Innovation Assessment}

The first step when it comes to defining innovation assessment, and the step to which I will restrict myself in the present article, is to determine the set of principles and practices that allow disruptive innovations to be fully assessed as they develop while avoiding the traps of technology assessment and impact assessment. With solidly defined principles and practices, I wish to initiate the conversation about the need for innovation assessment and the possible shapes that this can take. Subsequent contributions can then take up this call in more empirical detail by looking at case studies that approximate what we will come to understand as innovation assessment. Staying with the innovationas-stream metaphor, Fisher et al. (2006) have argued for a complementary 'midstream' integration of 
technical and societal elements, meant to link the open-endedness of the upstream with the concreteness of the downstream. They see this as the responsibility of scientists and engineers, working closer together to bring societal considerations to bear on their work. My contribution here is to argue that this midstream governance needs fleshing out within policy studies not only as a responsibility of scientists and engineers, but as a form of multi-stakeholder governance arrangement that lets regulators orchestrate, experiment and steer through disruptive periods.

\subsection{Principles of innovation assessment}

We can take the first steps towards conceptualising innovation assessment by appreciating the potential for disruptive innovations to instigate socio-technical controversies that policymakers cannot ignore. Controversies challenge what we know and accentuate what we do not know. Prevailing expectations are defied, co-operation breaks down, and a scramble ensues among participants to make sense of the disruption and establish a new understanding (Vollmer 2013). This means that disruptions-ascontroversies are inherently social activities, involving a number of different actors arguing over the meaning of objects and events. This also makes them socio-technical: in controversies, the boundaries between what is social and what is technical are constantly being negotiated. Technicality removes discussion from public debate, while sociality reintroduces it (Callon et al. 2009: 24-25). These dynamics result in the creation of hybrid forums: 'open spaces where groups can come together to discuss technical options involving the collective, hybrid because the groups involved and the spokespersons claiming to represent them are heterogeneous, including experts, politicians, technicians, and laypersons who consider themselves involved' (ibid:: 18). Within innovation assessment, the politics of expertise come starkly into focus due to the high degree of controversy of disruptive innovations. 
Because of controversy and the shifting barriers between what is social and what is technical, epistemic communities, who will also frequently find themselves internally divided over the scientific basis, have a difficult time 'speaking truth to power' (Haas 2004) and cannot be relied on as the sole source of an effective policy solution to innovation assessment. Epistemic communities are more effective when their members are homogeneous and share normative and causal beliefs (Seabrooke 2014: 55) - this is seldom the case with disruptive innovations. What complicates an exclusive or dominant reliance on experts even further is the demonstrated failure of 'deficit models' of public understanding of science that assume that the public is a blank slate easily won over by expert arguments - empirical evidence finds this to rarely be the case on controversial policy issues (e.g., Wynne 1996).

Hybrid forums bring opposed participants into direct confrontation with each other and the policy system and encourage an open debate that respects multiple perspectives on the salient issues and ways of knowing them. Different actors should not be compartmentalised into 'pure' groupings such as scientists, experts, industry, and civil society and kept at arm's length from each other - rather, policymakers should recognise that all the facts, standpoints and developments of the policy debate 'overflow' these neat borders and set off unexpected reactions in unforeseen domains (Callon et al. 2009: 28). For example, fracking is not just about groundwater, but about climate change, decarbonisation, job creation, and energy security, among many other things. The e-cigarette debate is not just about toxicity levels, but about pharmaceuticals, advertising, entrepreneurship, and tobacco control. Rather than attempt the impossible task of containing these overflows by straitjacketing them into specific impacts or anticipating their complex and rapid interactions according to a TA logic, an 
innovation assessment approach would set up multi-stakeholder processes to steer through the disruption, remaining flexible to allow for unexpected developments.

Table 1 below identifies the six main dimensions along which technology assessment, innovation assessment, and impact assessment vary. These dimensions may also be understood as principles to guide future manifestations of innovation assessment. Firstly, and most importantly, innovation assessment should balance the upstream emphasis of technology assessment with the downstream emphasis of impact assessment. Secondly, innovation assessment takes disruptive innovations as its objects of study rather than science and technology on the one hand or the impacts of policy options on the other. Thirdly, innovation assessment should bridge the long-term time horizon of technology assessment with the shorter-term time horizon of impact assessment. Fourthly, this requires that it takes an intermediate position between imagining innovations as highly flexible or completely fixed. Fifthly, the outcomes of innovation assessments should embrace hybrid forums in order to initiate multi-stakeholder processes that share responsibility for steering through the disruption. This differentiates innovation assessment from the scenarios, visions, and roadmaps of technology assessment on the one hand and the policy proposals of impact assessments on the other. Sixthly, innovation assessment should be built on a normative foundation of deliberative democracy as opposed to the cost-benefit analysis of impact assessment, emphasizing throughput legitimacy as opposed to mainly output legitimacy (Schmidt 2013). This mirrors the normative orientation of the more openended types of TA (such as the Danish or Dutch traditions). Taken in their entirety, these principles meet the dual challenges of salience and uncertainty by widely enrolling stakeholders and experts into the policy process and granting them co-ownership of the governance arrangement and eventual 
legislative outputs. In the next section, I propose a few different sources of inspiration from which a more concrete architecture of innovation assessment can be derived in future work. 
Table 1. The differences between technology assessment, innovation assessment, and impact assessment

\begin{tabular}{c|ccc}
\multirow{2}{*}{$\begin{array}{c}\text { Focus of analysis } \\
\text { Objects of study }\end{array}$} & Technology assessment & Innovation assessment & Impact assessment \\
\cline { 2 - 4 } Time horizon & Science and technology & Disruptive innovations & Policy options \\
Scope for change & Long-term & $\begin{array}{c}\text { Bridging long to short- } \\
\text { term }\end{array}$ & Short-term \\
Outcomes & High & Medium & Low \\
Normative & $\begin{array}{c}\text { Scenarios, visions, } \\
\text { roadmaps }\end{array}$ & $\begin{array}{c}\text { Multi-stakeholder } \\
\text { processes }\end{array}$ & Policy proposals \\
underpinnings & Varies & Deliberative democracy & Cost-benefit analysis
\end{tabular}

Source: Author.

\subsection{Inspirations for innovation assessment}

In turning the above principles into specific governance arrangements, innovation assessment can be helped along by considering past and emerging scholarship that rises to similar challenges. I will briefly reflect on experimentalist governance, orchestration, responsible research and innovation, and agile governance, all of which exhibit some common themes that innovation assessment should draw on, but none of which is sufficient to encompass the approach in its entirety.

Experimentalist governance describes the multi-level decision-making architecture of the EU as consisting of four key elements: framework goals, subsidiarity, monitoring, and revision (Sabel and 
Zeitlin 2008: 273-274). The idea is that overall policy goals are defined at the EU level and then left to lower-level units such as national ministries or regulatory authorities to implement as they see fit. In return for this subsidiarity, the lower-level units are expected to regularly report on progress and performance, which allows the higher-level framework goals, metrics, and procedures to be revised and updated. In the policy areas that approximate experimentalist governance (such as data privacy, financial markets, energy, competition, and food safety), the EU strikes a balance between soft law and overly hierarchical rule-making. This form of delegation and recursion is useful for dealing with complex and sensitive policy areas. Innovation assessment should similarly take an experimentalist approach while steering through periods of disruption by setting overall goals and carefully monitoring the effects of different policy options, the effects of any one policy being difficult to anticipate beforehand. This avoids frontloading the assessment of complex innovations that are still evolving, as well as jumping the gun on regulation that might be wide of the mark or unnecessarily restrain the development of the innovation.

Another form of delegation, which has much in common with experimentalism, is described by the 'orchestration' framework (Abbott et al. 2015). In orchestrated governance arrangements, policymakers refrain from engaging in hard regulation (or soft assessment) in order to mobilise and facilitate the voluntary cooperation of multiple intermediaries who are brought together in networks to steer the issue through coordination and information-sharing. The Commission already does something like this in telecommunications through the Body of European Regulators for Electronic Communications and in competition policy through the European Competition Network (Blauberger and Rittberger 2015). Orchestration when applied to EU policymaking places the Commission as 
orchestrator and networks of European and national regulatory agencies as the intermediaries and targets.

Like experimentalist governance, the theory emphasises the benefits of steering in-between hard and soft regulation. Both theories also present a perspective on the macro-level architecture of EU decision-making. The task for innovation assessment would be to translate the ideas contained within orchestration and experimentation to more micro-level settings that have traction on individual cases of assessment as they play out between the Commission and its stakeholders. For orchestration in particular, there is a challenge when it comes to the necessary criterion of goal alignment - because orchestration lacks mechanisms of command and control, goals must be aligned in order for voluntary cooperation to function. Such goal alignment may be difficult to achieve on especially controversial cases of disruption. For example, many environmental NGOs in Brussels oppose any form of fracking whatsoever, which makes it difficult to imagine their participation in regulatory initiatives that go short of completely banning the practice. This requires that innovation assessment must start early and allow all options to be on the table initially.

The Commission has previously given some thought to how research and innovation can be made more responsible and sensitive to societal needs (von Schomberg 2013). Responsible research and innovation (RRI) has emerged as a core concept of European innovation and research policy, in particular within the Science in Society Programme of the Horizon 2020 Strategy (Owen et al. 2012). RRI is mostly understood as a form of background orientation towards science, technology, and innovation policy at the earliest stages, and has less to do with addressing sudden, disruptive regulatory challenges. That said, it shares with technology assessment a number of characteristics that have the potential to align innovation more closely with societal needs (Lindner et al. 2016): an emphasis on 
shared responsibility and deliberation, as well as flexible and adaptable outcomes that work at multiple levels of governance. It also shares with impact assessment the recognition that such principles require a strong institutionalisation in order to foster supportive environments that have a chance of impacting policy. Within the EU's institutional architecture, RRI resides mostly within DG Research. Innovation assessment should explore ways of building on the principles of RRI and incorporating them more concretely into the policy process throughout the Commission.

Finally, 'agile governance' as a regulatory approach has recently been proposed by the World Economic Forum (2016). The idea behind agile governance is to copy the agile principles of software development and translate them to a political setting, the benefit of which would be to make governance more flexible and reactive to fast-moving changes. Agile governance adheres to four principles: outcomes over rules (implying experimentation, monitoring, and incremental change), responding to change over following a plan (implying flexibility and dynamic adaptation), participation over control (implying shared responsibility and enrolment of multiple stakeholders), and selforganisation over centralisation (implying delegation and empowerment of participants). Clearly, agile governance already chimes very well with the other sources of inspiration I have identified in this section, and with the principles of innovation assessment in general.

The task remains to translate these principles into concrete governance arrangements and tools, but in highlighting the multiple overlaps between these disparate sources of inspiration, we are convinced of the need and interest for the endeavour, and how this would contribute directly to addressing the challenges of regulating disruptive innovations.

All of these sources of inspiration coalesce around three common themes: networks, deliberation, and experimentation. Bringing multiple stakeholders together in network structures is a way of 
embracing the hybrid forums that come into being around socio-technical controversies, and their facilitation and organization should be encouraged by policymakers rising to the challenges of innovation assessment. The way to secure participation is by granting co-ownership of the policymaking process and keeping all options and perspectives on the table, at least initially, to facilitate an open deliberation of ways forward. To avoid this becoming an inconsequential 'talking shop', the innovation assessment should be integrated into the policymaking process so it is directly linked to possible legislative outcomes - there should be something at stake and a clear incentive for participation. Finally, an experimental approach lets the multi-stakeholder network commonly assess the merits and outcomes of various approaches and deliberate on their pros and cons, all the while remaining flexible to unanticipated changes to the innovation in question.

\section{Concluding Remarks}

Current regulatory logics at the EU-level are ill-equipped to face the challenges of disruptive innovation. The problem manifests itself particularly within the realm of assessment regimes, where regulators are pressed into treating disruptions either as technologies or impacts. This false dichotomy between upstream governance and downstream governance of innovations overlooks the fertile middle ground between them as containing the seeds of a form of 'midstream' innovation assessment. Innovation assessment, properly conceived, will contribute by steering innovations through their most disruptive periods, where multiple different forms and trajectories are still possible, rather than just reacting to their impacts or discussing the technologies on which they are based. It is extremely important to get the governance arrangements of disruptive innovations 'right'. Impact assessments that over-regulate too early in the life of an innovation risk closing off possible trajectories that could have societal value by solidifying one particular understanding of the innovation and restricting 
experimentation. On the other hand, technology assessments that do too little run the risk of letting the market decide completely in ways that might lead to undesirable externalities that could have been prevented. To avoid these risks, I identified a number of characteristics and principles that innovation assessment should live up to, and looked for inspiration for specific governance arrangements and policy tools in orchestration, experimentalist governance, RRI, and agile governance.

This article has focused on defining the problem of the missing middle of assessment regimes as a problem in the first place. I have emphasised the conceptual side of things in order to illustrate the problem as a general phenomenon, and I have begun the work of defining the principles and sources of inspiration from which more concrete policy tools can be built. While it is a limitation of the article that more concrete tools and arrangements still need to be developed, there are a number of practical considerations that policymakers can already take home. Table 1 can be condensed into the following three recommendations:

1. Do more with less. Innovation assessment does not imply a new set of overly bureaucratic and comprehensive arrangements that carry a risk of the Commission being accused of regulatory overreach. Rather, it implies a lighter-touch approach that does more to $i$ ) involve stakeholders in regulatory networks and forums before and during the drafting of policy proposals and ii) allows for increased degrees of experimentation at the implementation stage. It is a shift in logic from trying to get things perfectly right from the outset to correcting the course of development as innovations unfold.

2. Be humble. Recognise that both lay and expert knowledge can provide valuable inputs to the regulatory process. They complement each other by filling out the blind spots of their counterpart. By enrolling both into multi-stakeholder processes, the twin pitfalls of technocracy 
and populism are averted. This is doubly important when it comes to disruptions, given the unclear state of the scientific evidence base that tends to characterize novel and controversial phenomena.

3. Be ambitious. Although this sounds like a contradiction to the second recommendation, it is in reality a supplement. Much debate on the regulation of disruptions gets stuck either in a mire of technical details or in inconsequential hypothetical discussion about too-distant futures. Ambition here means taking a firm stance, developed in cooperation with involved stakeholders, on the direction in which to steer innovations, aiming for those trajectories that bridge short-term realities with long-term goals.

When we study how policymakers respond to the challenges of disruptive innovations, not only do we open up a new area of inquiry on the intersection of policy and innovation studies; we also shed new light on the challenges of making effective and legitimate policy that manages to balance the viewpoints, interests and knowledge of attentive publics and experts. For public policy, the article has brought attention to disruptive innovations as a class of policy problems that speak directly to the politics of expertise and policy appraisal. In doing so, I have argued that the study of assessment regimes ought to broaden in two directions. First, rather than just focusing on impact assessments, we should consider the full range of assessment exercises, as well as the highly political games that go into choosing between assessment regimes, organizing evidence and data within them, and dictating what the assessments are used for. Second, we should imagine and describe new forms of assessment, such as innovation assessment, that can rise to novel regulatory challenges.

\section{Biographical note}


Jacob A. Hasselbalch is a postdoctoral researcher at Copenhagen Business School.

Orcid ID: orcid.org/0000-0001-5491-7023

\section{Address for correspondence}

Steen Blichers Vej 22, 2000 Frederiksberg, Denmark

Email: jaha.dbp@cbs.dk

\section{Acknowledgements}

In addition to the three anonymous reviewers, the author wishes to thank the following people for guidance and comments on earlier versions of the article: Cornel Ban, Christopher Bennett, Susana Borrás, André Broome, Martin Bæk Carstensen, Louise Thorn Bøttkjær, Lea Foverskov, Stine Haakonsson, Alan Irwin, Matthias Kranke, Mart Laatsit, Ralf Lindner, Jean-Frédéric Morin, Leonard Seabrooke, and Duncan Wigan.

\section{References}

Abbott, K. W., Genschel, P., Snidal, D. and Zangl, B. (eds) (2015) International Organizations as Orchestrators, Cambridge: Cambridge University Press.

Adelle, C., Jordan, A. and Turnpenny, J. (2012) 'Proceeding in parallel or drifting apart? A systematic review of policy appraisal research and practices', Environment and Planning C: Government and Policy 30(3): 401-415.

Blauberger, M. and Rittberger, B. (2015) 'Conceptualizing and theorizing EU regulatory networks', Regulation and Governance 9(4): 367-376. 
Cagnin, C., Havas, A. and Saritas, O. (2013) 'Future-oriented technology analysis: Its potential to address disruptive transformations', Technological Forecasting and Social Change 80(3): 379385.

Callon, M., Lascoumes, P. and Barthe, Y. (2009) Acting in an Uncertain World. An Essay on Technical Democracy, Cambridge, MA: MIT Press.

Christensen, C. M. (1997) The Innovator's Dilemma: When New Technologies Cause Great Firms to Fail, Boston, MA: Harvard Business Review Press.

Council of the European Union (2016a) Outcome of the council meeting: 3470th Council meeting. Competitiveness (Internal Market, Industry, Research and Space), available at http://www.consilium.europa.eu/en/meetings/compet/2016/05/st09357_en16_pdf/ (accessed June 2017).

Council of the European Union (2016b) Recommendation for a Council Recommendation on the establishment of National Productivity Boards - Transmission to the European Council, available at http://data.consilium.europa.eu/doc/document/ST-10083-2016-INIT/en/pdf (accessed June 2017).

Delvenne, P., Fallon, C. and Brunet, S. (2011) 'Parliamentary technology assessment institutions as indications of reflexive modernization', Technology in Society 33(1-2): 36-43, doi:10.1016/j.techsoc.2011.03.004.

Dinan, D. (2016) 'Governance and Institutions: A More Political Commission', Journal of Common Market Studies 54: 101-116.

Dunlop, C. A., Maggetti, M., Radaelli, C. M. and Russel, D. (2012) 'The many uses of regulatory 
impact assessment: A meta-analysis of EU and UK cases', Regulation and Governance 6(1): 2345.

Ely, A., Van Zwanenberg, P. and Stirling, A. (2014) 'Broadening out and opening up technology assessment: Approaches to enhance international development, co-ordination and democratisation', Research Policy 43(3): 505-518, doi:10.1016/j.respol.2013.09.004.

European Commission (2014) About FTA 2014, Joint Research Centre of the European Commission, available at https://ec.europa.eu/jrc/en/event/site/fta2014/about (accessed July 2016).

European Commission (2015a) Better Regulation Agenda: Enhancing transparency and scrutiny for better EU law-making (Press Release IP/15/4988), Press Release Database, available at http://europa.eu/rapid/press-release_IP-15-4988_en.htm (accessed February 2017).

European Commission (2015b) Guidelines on Impact Assessment, Better Regulation Guidelines, available at http://ec.europa.eu/smart-regulation/guidelines/ug_chap3_en.htm (accessed February 2017).

European Commission (2016) Better regulations for innovation-driven investment at EU level. Commission Staff Working Document, available at https://ec.europa.eu/research/innovationunion/pdf/innovrefit_staff_working_document.pdf (accessed August 2017).

European Political Strategy Centre (2016) Towards an Innovation Principle Endorsed by Better Regulation, $\quad$ EPSC Strategic Notes, available at https://ec.europa.eu/epsc/sites/epsc/files/strategic_note_issue_14.pdf (accessed June 2017).

European Strategy and Policy Analysis System (2015) Global Trends to 2030: Can the EU meet the challenges ahead?, available at http://europa.eu/espas/pdf/espas-report-2015.pdf (accessed July 
2016).

Fisher, E., Mahajan, R. L. and Mitcham, C. (2006) 'Midstream Modulation of Technology: Governance From Within', Bulletin of Science, Technology \& Society 26(6): 485-496.

Forsberg, E. M., Thorstensen, E., Nielsen, R. Ø. and de Bakker, E. (2014) 'Assessments of emerging science and technologies: Mapping the landscape', Science and Public Policy 41(3): 306-316.

Haas, P. (2004) 'When does power listen to truth? A constructivist approach to the policy process', Journal of European Public Policy 11(4): 569-592.

Hasselbalch, J. (2016) 'Professional disruption in health regulation: electronic cigarettes in the European Union', Journal of Professions and Organization 3(1): 62-85, doi:10.1093/jpo/jov009.

Kaiser, M., Kurath, M., Maasen, S. and Rehman-Sutter, C. (eds) (2010) Governing Future Technologies. Nanotechnology and the Rise of an Assessment Regime, Dordrecht, Heidelberg, London \& New York: Springer.

Kay, A. (2005) 'A Critique of the Use of Path Dependency in Policy Studies', Public Administration 83(3): 553-571, doi:10.1111/j.0033-3298.2005.00462.x.

Lindner, R. et al. (eds) (2016) Navigating Towards Shared Responsibility in Research and Innovation. Approach, Process and Results of the Res-AGorA Project, Karlsruhe: Fraunhofer ISI.

Lundvall, B.-Å. and Borrás, S. (2005) 'Science, Technology, and Innovation Policy’, in J. Fagerberg, D. C. Mowery, and R. R. Nelson (eds). The Oxford Handbook of Innovation. Oxford: Oxford University Press, pp. 599-631.

Owen, R., Macnaghten, P. and Stilgoe, J. (2012) 'Responsible research and innovation: From science 
in society to science for society, with society', Science and Public Policy 39(6): 751-760.

Parson, E. A. (1995) 'Integrated assessment and environmental policy making. In pursuit of usefulness', Energy Policy 23(4-5): 463-475.

Radaelli, C. M. (1999) 'The public policy of the European Union: whither politics of expertise?', Journal of European Public Policy 6(5): 757-774.

Radaelli, C. M., Dunlop, C. A. and Fritsch, O. (2013) 'Narrating Impact Assessment in the European Union', European Political Science 12(4): 500-521.

Sabel, C. F. and Zeitlin, J. (2008) 'Learning from Difference: The New Architecture of Experimentalist Governance in the EU', European Law Journal 14(3): 271-327, doi:10.1111/j.14680386.2008.00415.x.

Schaper-Rinkel, P. (2013) 'The role of future-oriented technology analysis in the governance of emerging technologies: The example of nanotechnology', Technological Forecasting and Social Change 80(3): 444-452, doi:10.1016/j.techfore.2012.10.007.

Schmidt, V. A. (2013) 'Democracy and Legitimacy in the European Union Revisited: Input, Output and "Throughput", Political Studies 61(1): 2-22.

Seabrooke, L. (2014) 'Epistemic Arbitrage: Transnational Professional Knowledge in Action', Journal of Professions and Organization 1(1): 49-64.

Stirling, A. (2008) “"Opening Up” and "Closing Down”: Power, Participation, and Pluralism in the Social Appraisal of Technology', Science, Technology \& Human Values 33(2): 262-294, doi:10.1177/0162243907311265. 
Torriti, J. (2010) 'Impact assessment and the liberalization of the EU energy markets: Evidence-based policy-making or policy-based evidence-making?', Journal of Common Market Studies 48(4): $1065-1081$.

Vollmer, H. (2013) The Sociology of Disruption, Disaster and Social Change: Punctuated Cooperation, Cambridge: Cambridge University Press.

von Schomberg, R. (2013) ‘A Vision of Responsible Research and Innovation’, in R. Owen, M. Heintz, and J. Bessant (eds). Responsible Innovation: Managing the Responsible Emergence of Science and Innovation in Society. London: John Wiley, pp. 51-74.

World Economic Forum (2016) A Call for Agile Governance Principles, 2016, available at http://www3.weforum.org/docs/IP/2016/ICT/Agile_Governance_Summary.pdf ～(accessed February 2017).

Wynne, B. (1975) 'The rhetoric of consensus politics: a critical review of technology assessment', Research Policy 4(2): 108-158.

Wynne, B. (1996) 'May the Sheep Safely Graze? A Reflexive View of the Expert-Lay Knowledge Divide', in S. Lash, B. Szerszynski, and B. Wynne (eds). Risk, Environment and Modernity: Towards a New Ecology. London: SAGE Publications, pp. 44-83. 
WORD COUNT: 7,960 